[When citing this chapter, refer to Behaviour 152 (2015) 247-258]

Editorial

\title{
Moving bonobos off the scientifically endangered list
}

\author{
Brian Hare $^{\mathrm{a}, \mathrm{b}, *}$ and Shinya Yamamoto ${ }^{\mathrm{c}, \mathrm{d}}$ \\ ${ }^{a}$ Department of Evolutionary Anthropology, Duke University, 104 Biological Sciences \\ Building, Box 90383, Durham, NC 27708-9976, USA \\ ${ }^{\mathrm{b}}$ Center for Cognitive Neuroscience, Levine Science Research Center, Duke University, \\ Box 90999, Durham, NC 27708, USA \\ ${ }^{\mathrm{c}}$ Graduate School of Intercultural Studies, Kobe University, \\ 1-2-1 Tsurukabuto, Nada-ku, 657-8501 Kobe, Japan \\ ${ }^{\mathrm{d}}$ Wildlife Research Center, Kyoto University, Yoshida-honmachi, \\ Sakyo-ku, Kyoto 606-8501, Japan \\ *Corresponding author's e-mail address: b.hare@duke.edu
}

Accepted 14 January 2015; published online 2 February 2015

\begin{abstract}
This Special Issue of Behaviour includes twelve novel empirical papers focusing on the behaviour and cognition of both captive and wild bonobos (Pan paniscus). As our species less known closest relative, the bonobo has gone from being little studied to increasingly popular as a species of focus over the past decade. We suggest that bonobos are ready to come off the scientific endangered list as a result. This Special Issue is exhibit A in showing that a renaissance in bonobo research is well underway. In this Editorial we review a number of traits in which bonobos and chimpanzees are more similar to humans than they are each other. We show how this means that bonobos provide an extremely powerful test of ideas about human uniqueness as well as being crucial to determining the evolutionary processes by which cognitive traits evolve in apes. This introduction places the twelve empirical contributions within the Special Issue in the larger evolutionary context to which they contribute. Overall this Special Issue demonstrates how anyone interested in understanding humans or chimpanzees must also know bonobos.
\end{abstract}

\section{Editorial}

Almost twenty years ago Frans de Waal and Frans Lanting married art and science in publishing the book Bonobos: The forgotten ape (de Waal \& Lanting, 1997). The book tells the story of our closest relative that has been largely ignored by both the public and Western science alike. Compared to

This is an open access chapter distributed under the terms of the prevailing CC-BY-NC License at the time of publication. 
our other close relative the chimpanzee, bonobos were only recently recognized as a species, have been little studied, and are little known to the general public as a result. This can distort our view of ape and human evolution, but worse makes this endangered species particularly vulnerable to extinction since a much smaller group of scientists are involved in protecting them. The book remains a call to action for behavioural scientists in particular to give bonobos the equal attention they deserve.

Perhaps The forgotten ape's biggest contribution is to make it clear that the lack of attention is largely an accident of history and not that chimpanzees inherently have more to teach us. Nowhere is the scientific value of bonobos more obvious then when trying to answer questions about how ape and human cognition evolves. Bonobos and chimpanzees are each more similar to humans than they are to each other across a number of traits that also need to be explained relative to our own species' evolution (Table 1). This means that understanding how bonobos and chimpanzees diverged from one another can allow for inference about cognitive evolution in similar traits in our own species (Hare, 2007, 2009, 2011). These significant phenotypic differences are particularly exciting given how genetically similar the two species are. Comparisons between bonobos and chimpanzees raise the spectre of identifying the genetic basis and evolutionary origin of traits that otherwise would be too technically challenging to tackle given the relative gulf between human and chimpanzee (Prufer et al., 2012). Moreover, a careful comparison of traits likes those in Table 1 show the danger of only considering chimpanzees when determining what behavioural or cognitive traits in humans are unique. Focusing exclusively on human comparisons to chimpanzees would lead us to erroneously conclude that humans are unique among apes for nonconceptive sex, a reliance on mothers in adulthood, for showing adult play, sharing with strangers or having female alliances. For each of these traits bonobos are more similar to humans than to chimpanzees - meaning these traits are either shared between bonobos and humans through common descent or convergent evolution. Either outcome will be extremely important in understanding the evolution of these traits in humans.

With the publication of this Special Issue of Behaviour we are signalling that the bonobo is ready to be moved off the scientific endangered list. Pan paniscus has gone from forgotten to popular as a species for scientific study. With relative stability within bonobo habitat in the Democratic Republic of Congo over the past decade, field researchers are observing wild bonobos 


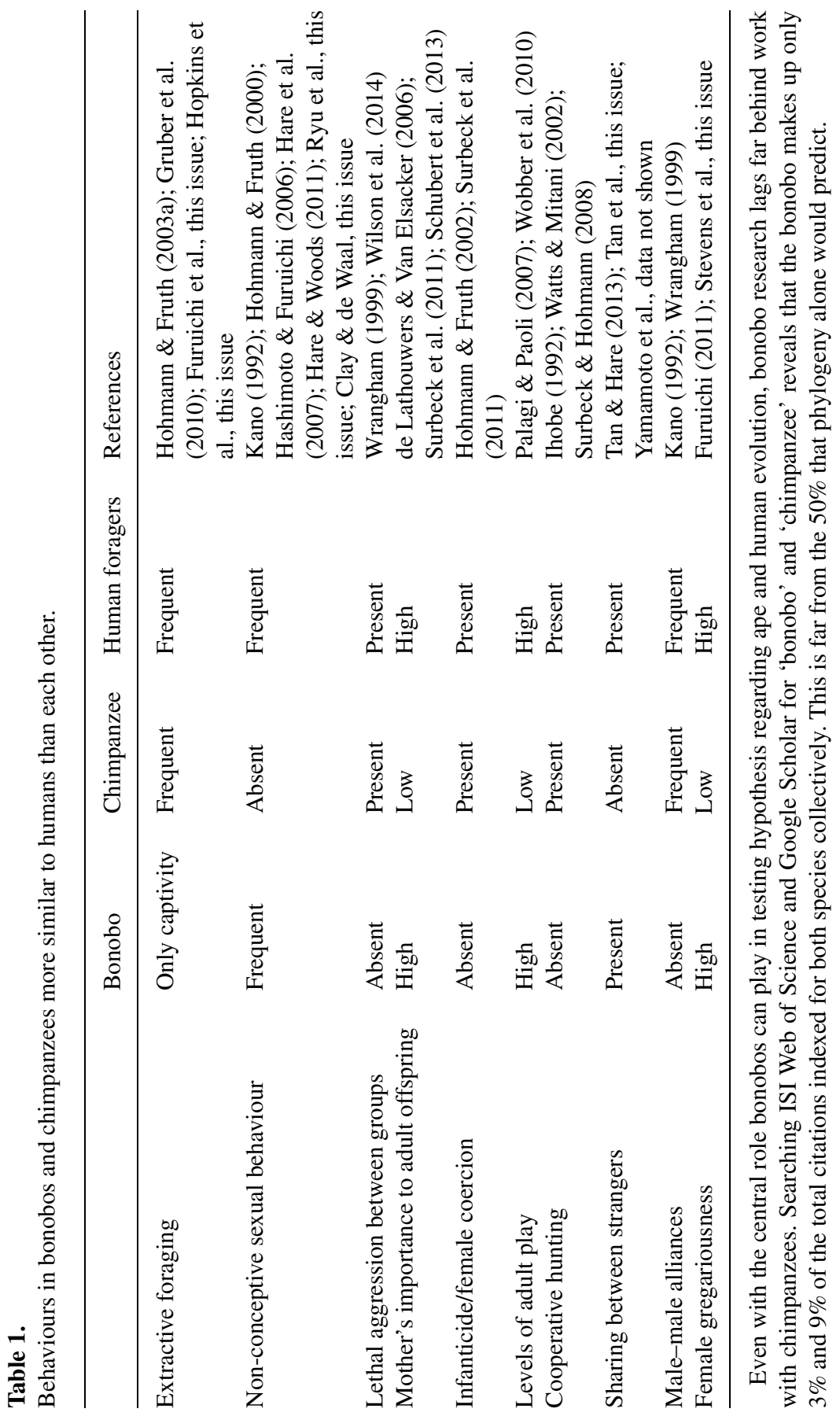




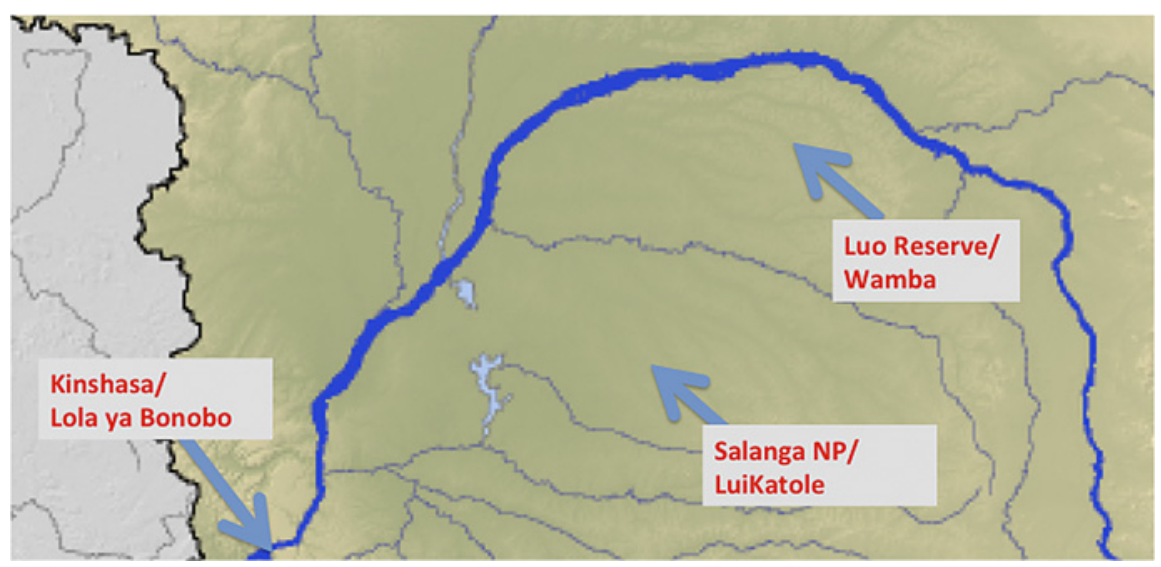

Figure 1. Bonobos are endangered and are only endemic to tropical forest South of the Congo River in the Democratic Republic of Congo. Their suspected historical range (approx. $500000 \mathrm{~km}^{2}$ ) is nearly the size of France and bigger than California (see http://www. iucnredlist.org/details/full/15932/0). The map shows the Congo River and the location of the most productive research sites over the last decade for bonobo behaviour and cognition. Wamba in the Luo Reserve represents the first and oldest study of wild bonobos established in 1973 by Takayoshi Kano (Kano, 1992), Lui Katole in Salonga National Park has likely been the most productive study site on wild bonobos after over a decade of support from the Max Planck Society (Hohmann \& Fruth, 2003b), and Lola ya Bonobo Sanctuary outside the capital of Kinshasa has allowed for dozens of cognitive and developmental studies focusing on the sanctuaries' rehabilitated orphan bonobos rescued from the bushmeat trade (Wobber \& Hare, 2011). Map from wikicommons: File:CongoLualaba_watershed_topo.png. This figure is published in colour in the online edition of this journal, which can be accessed via http:// booksandjournals.brillonline.com/content/journals/1568539x.

more than ever and Lola ya Bonobo, the bushmeat orphanage in Kinshasa, has hosted scores of researchers from over a dozen institutions (Figure 1). Moreover, researchers have increasingly published on bonobo behaviour from zoo populations - particularly bonobo colonies in Europe. Captive bonobo researchers have also finally begun to break the shackles of small sample size from which most bonobo research has long suffered. Lola ya Bonobo has allowed for a series of large-scale experimental comparisons of behaviour and cognition between the two Panins where at least 20-30 individuals of each species have participated (e.g., Hare et al., 2007; Herrmann et al., 2010, 2011; Wobber et al., 2010a, b, 2014; Maclean \& Hare, 2012, 2013; Rosati \& Hare, 2012, 2013). Researchers in European zoos have also been able to collaborate and boost sample sizes. A number of recent studies have sampled several zoo populations and allow for powerful analyses (Stevens et 
al., 2007; Jaeggi et al., 2010; Behringer et al., 2014a, b). These experiments and large-scale studies have corroborated many earlier observational studies (e.g., de Waal, 1987; Kuroda, 1989; Kano, 1992), revealed many new phenomenon, and suggested at least one novel hypothesis for bonobo evolution (Hare et al., 2012). Thus, this Special Issue is exhibit A in demonstrating that a renaissance in bonobo research is well underway.

The issue includes a dozen new empirical papers from the wild and captivity illustrating why anyone wanting to understand humans or chimpanzees must also know bonobos. Bonobos are not only equal to chimpanzees as our relatives, but they are also unique (see Table 1). The majority of papers in this issue show that whether you are interested in the evolution of culture and tool use, social relationships and sharing or foraging ecology and cognition, bonobos have a major contribution to make.

The bonobo female is the focus of four papers that further show exactly how unusual bonobo female relationships are. Stevens and colleagues examine relationship value in bonobos by observing social interactions in one of the world's largest zoo colonies of bonobos. They report that unlike chimpanzees who show the strongest relationship values between males, bonobos show the strongest values between females. Ryu and colleagues present evidence that bonobo swellings may act to attract females as much as males. In comparison to female chimpanzees whose swellings are only attractive to males and act as honest indicators of ovulation, bonobos are more like humans in disguising their ovulation. Ryu and colleagues present new evidence that the extended swelling cycle in bonobos is as crucial to cementing relationships between females as they are in attracting males. Clay and de Waal revisit the question of the function of bonobo sexual contact. They find evidence that bonobo sexual contact is in large part about conflict resolution. Bonobos - and in particular female bonobos — often make social sexual contact during reconciliation or consolation events following a conflict. Unlike chimpanzees, bonobos are able to use genital contact and social sexual behaviour to maintain relatively low intensity aggression. Finally, Yamamoto reports that the bonobos at the Wamba field site frequently shared pieces of large fruit that are seasonally available. Unlike chimpanzees where most sharing occurs between males, in bonobos the majority of sharing occurred between adult females. In addition, this paper suggests the existence of 'courtesy' food sharing characterized by begging for social bond rather than food itself, since the recipients begged for fruit, which could be ob- 
tained by themselves without any cooperation or specialized skills. This is proposed to enhance female-female bonding in bonobos. All four papers provide further evidence that the behaviour and psychology of bonobo females is radically different from that observed in chimpanzees.

Foraging behaviour and cognition of bonobos is the focus of three papers that each show important ways that bonobos spatial cognition differs remarkably from chimpanzees. Beaune and colleagues present years of field data from the Lui Katole site that shows the pattern of seed dispersal in bonobos. They find that in violation of optimal foraging theory bonobos homogenously disperse a variety of fruits that vary in both the quality and quantity at the patch of origin. Plants are thought to evolve strategies to manipulate the dispersal patterns of their dispersers, but this is not the case in bonobos apparently. Instead, bonobos uniformly disperse seeds a minimum of $100 \mathrm{~m}$ and typically as much as a kilometre away from their origin. This suggests that the quality and quantity of food a tree provides does not affect the foraging decisions that bonobos make on a daily basis. Two studies on foraging cognition might help explain how cognitive abilities may free bonobos from being manipulated by plant evolution similar to other species. Rosati reports a set of experiments that measure the spatial memory strategies that bonobos rely on when searching for food. Bonobos are clearly not completely egocentric and show evidence of using an allocentric - or more flexible landmark based strategy to remember things. But what is most interesting is what is not observed - a developmental shift seen in chimpanzees. Further, Wobber and Herrmann test for the possible link between testosterone and cognition found in other species. While they find the familiar pattern of male testosterone and spatial cognition being linked in chimpanzees they find no such link in male bonobos. This adds to the growing evidence that the hormonal profile of bonobos — and in particular male bonobos — seems to differ significantly from chimpanzees. Bonobos are the ultimate seed dispersers in the Congo Basin, have the ability to use landmarks when finding things in space but violate optimal foraging theory, and unlike chimpanzees develop these abilities differently and are unaffected by testosterone. Bonobos seem to break all the rules when it comes to foraging.

Two papers are relevant to solving the puzzle of why bonobos are expert extractive foragers in captivity but have never been seen using tools to obtain food in the wild. Furuichi and colleagues provide powerful new data 
from Wamba to document that while bonobos do have a rich tool use tradition in Wamba they do not use tools from extractive foraging as seen in chimpanzees at a comparable site in Congo-Brazzaville. More interesting is the fact that ecological differences between the two sites do not seem to explain the prevalence of extractive foraging in the chimpanzees and the lack of this type of tool use in bonobos. Hopkins and colleagues conducted experimental comparisons of handedness in bonobos and chimpanzees. While chimpanzees have been repeatedly shown to show right hand bias, bonobos do not show the same lateralized pattern as chimpanzees. Hopkins and colleagues suggest that the chimpanzee pattern may be a result of their increased reliance on tools while the bonobo pattern may be more representative of the basal state in our last common ancestor. The two papers raise as many questions as they answer and make bonobo tool use one of the biggest puzzles within cognitive ethology.

What is particularly exciting is that for the first time captive and wild bonobos are regularly being directly compared to chimpanzees. This work is not only highlighting ways in which bonobos are different, but also surprising ways they are the same. Finding similarity is as important as finding differences since it puts any differences into a larger phenotypic context. Three papers in this issue also reveal surprising similarities. Maclean and Hare test the hypothesis that bonobos will be more skilled at reading human cooperative - communicative intentions than chimpanzees. Despite their prediction both species were equally skilled in reading cooperative - communicative gestures and equally unskillful at reading the same gestures in a more competitive context. The results suggest that both bonobos and chimpanzees differ from human infants in their use of human gestures in a similar way. Tan and colleagues tested whether bonobos would show a prosocial tendency in what has become a 'standard' paradigm to test for proactive sharing in nonhumans. Despite recent evidence suggesting that bonobos might show a strong tendency to share in this same paradigm where chimpanzees do not, the authors found no evidence for proactive sharing. However, they interpret the results to suggest that there are major limitations to the paradigm used and that it should be abandoned in favor of other assessments of prosociality that have been successfully validated across species. Finally, SchroepferWalker and Hare experimentally measure the effect of grooming and play on the social preferences of bonobos and chimpanzees. While it has long been assumed that non-food social currencies such as grooming and play 
carry social value, this assumption has never been explicitly tested. The authors find that both bonobos and chimpanzees shift their preferences toward a human who recently groomed or played with them even though no food was exchanged. Both species can shift social preference based on the social currency of grooming or play alone. Interestingly against the authors predictions the two species did not differ in how their preferences shifted with males of both species showing a robust effect and females showing a small or non-significant shift.

Taken together this new body of work clearly shows that progress is being made understanding in what way bonobos and chimpanzees share traits and where they do not - as well as pointing to very exciting directions for future research. Given the quantity and quality of research being produced, we predict a very exciting future for bonobo research. This means the future is also bright for a better understanding of our species' evolution as well as understanding primate behaviour more generally. Despite growing momentum there are still major pieces of infrastructure that are missing for sustainable growth. The first and most obvious is the simple fact that we are unaware of a dedicated bonobo field researcher that has received a tenure-tracked assistant professorship at a major research university in the past decade or more. Over the same period a host of researchers focused primarily on chimpanzee behaviour have deservedly taken up positions at top universities. Things should become more balanced soon as a new crop of young bonobo researchers - many of whom published in this issue - are reaching the stage where they will successfully compete for future positions. Likewise, as more high impact research is produced departments will want to lead in this exciting area of research. Another gap that must be filled is the shortage of Congolese scientists that focus primarily on bonobo behaviour or conservation (i.e., only one paper in the current Special Issue includes a Congolese collaborator). It will be these scientists that teach the Congolese public, politicians and students about the value of the only ape that is $100 \%$ Congolese. Finally, primatologists across the board desperately need to pivot to Asia. China, in particular, is having increasing influence on all areas where endangered primates live - the Congo Basin being no exception. Students need to be recruited from China to work with apes in Africa, conferences on conservation need to be held there and Chinese academics and zoological societies must be engaged to build a vibrant conservation community that can respectfully respond to future challenges. We are hopeful that progress 
will be made in these areas rapidly and we hope that this Special Issue plays a small role in moving bonobo research into the forefront where it belongs. The bonobo is forgotten no more!

\section{References}

Beaune, D., Bretagnolle, F., Bollache, L., Hohmann, G. \& Fruth, B. (2015). Can fruiting plants control animal behavior and seed dispersal distance? - Behaviour 152: 359-374.

Behringer, V., Deschner, T., Deimel, C., Stevens, J. \& Hohmann, G. (2014a). Age related changes in urinary testosterone levels suggest differences in puberty onset and divergent life history strategies in bonobos and chimpanzees. - Horm. Behav. 66: 525-533.

Behringer, V., Deschner, T., Murtagh, R., Stevens, J. \& Hohmann, G. (2014b). Age-related changes in Thyroid hormone levels of bonobos and chimpanzees indicate heterochrony in development. - J. Hum. Evol. 66: 83-88.

Clay, Z. \& de Waal, F.B.M. (2015). Sex and strife: post conflict sexual contacts in bonobos. - Behaviour 152: 313-334.

de Lathouwers, M. \& Van Elsacker, L. (2006). Comparing infant and juvenile behavior in bonobos (Pan paniscus) and chimpanzees (Pan troglodytes): a preliminary study. Primates 47: 287-293.

de Waal, F.B.M. (1987). Tension regulation and non-reproductive functions of sex in captive bonobos. - Nat. Geogr. Res. 3: 318-335.

de Waal, F.B.M. \& Lanting, F. (1997). Bonobo: the forgotten ape. - California University Press, Berkeley, CA.

Furuichi, T. (2011). Female contributions to the peaceful nature of bonobo society. - Evol. Anthropol. 20: 131-142.

Furuichi, T., Sanz, C., Koops, K., Sakamaki, T., Ryu, H., Tokuyama, N. \& Morgan, D. (2015). Why do wild bonobos not use tools like chimpanzees do? - Behaviour 152: 425-460.

Gruber, T., Clay, Z. \& Zuberbühler, K. (2010). A comparison of bonobo and chimpanzee tool use: evidence for a female bias in the Pan lineage. - Anim. Behav. 80: 1023-1033.

Hare, B. (2007). From nonhuman to human mind: what changed and why. - Curr. Dir. Psychol. Sci. 16: 60-64.

Hare, B. (2009). What is the effect of affect on bonobo and chimpanzee problem solving? In: The neurobiology of the umwelt: how living beings perceive the world (Berthoz, A. \& Christen, Y., eds). Springer, Berlin, p. 89-102.

Hare, B. (2011). From hominoid to hominid mind: what changed and why? - Ann. Rev. Anthropol. 40: 293-309.

Hare, B. \& Woods, V. (2011). Bonobo but not chimpanzee infants use socio-sexual contact with peers. - Primates 52: 111-116.

Hare, B., Melis, A., Woods, V., Hastings, S. \& Wrangham, R. (2007). Tolerance allows bonobos to outperform chimpanzees in a cooperative task. — Curr. Biol. 17: 619-623.

Hare, B., Wobber, T. \& Wrangham, R. (2012). The self-domestication hypothesis: bonobo psychology evolved due to selection against male aggression. - Anim. Behav. 83: 573585. 
Hashimoto, C. \& Furuichi, T. (2006). Comparison of behavioral sequence of copulation between chimpanzees and bonobos. - Primates 47: 51-55.

Herrmann, E., Hare, B., Call, J. \& Tomasello, M. (2010). Differences in the cognitive skills of bonobos and chimpanzees. - PLoS One 5: e12438.

Herrmann, E., Hare, B., Cisseski, J. \& Tomasello, M. (2011). The origins of human temperament: children avoid novelty more than other apes. — Dev. Sci. 14: 1393-1405.

Herrmann, E., Keupp, S., Hare, B., Vaish, A. \& Tomasello, M. (2013). Direct and indirect reputation formation in great apes and human children. — J. Comp. Psychol. 127: 63-75.

Hohmann, G. \& Fruth, B. (2000). Use and function of genital contacts among female bonobos. - Anim. Behav. 60: 107-120.

Hohmann, G. \& Fruth, B. (2002). Dynamics in social organization of bonobos (Pan paniscus). — In: Behavioural diversity in chimpanzee (Boesch, C., Marchant, L. \& Hohmann, G., eds). Cambridge University Press, Cambridge, p. 138-150.

Hohmann, G. \& Fruth, B. (2003a). Culture in bonobos? Between-species and within-species variation in behavior. - Curr. Anthropol. 44: 563-609.

Hohmann, G. \& Fruth, B. (2003b). Lui Kotal - a new site for field research on bonobos in Salonga National Park. — Pan African News 10: 25-27, available online at http://mahale. main.jp/PAN/10_2/10(2)_05.html.

Hopkins, W., Schaeffer, J., Russell, J., Bogart, S., Meguerditchian, A. \& Coulon, O. (2015). A comparative assessment of handedeness and its potential neuroanatomical correlates in chimpanzees and bonobos. - Behaviour 152: 461-492.

Ihobe, H. (1992). Male-male relationships among wild bonobos at Wamba, Republic of Zaire. - Primates 33: 163-179.

Jaeggi, A., Stevens, J. \& van Schaik, C. (2010). Tolerant food sharing and reciprocity is precluded by despotism among bonobos but not chimpanzees. - Am. J. Phys. Anthropol. 143: 41-51.

Kano, T. (1992). The last ape: pygmy chimpanzee behavior and ecology. — Stanford University Press, Stanford, CA.

Kuroda, S. (1989). Developmental retardation and behavioral characteristics of pygmy chimpanzees. - In: Understanding chimpanzees (Heltne, P. \& Marquardt, L., eds). Harvard University Press, Cambridge, MA, p. 184-193.

Maclean, E. \& Hare, B. (2012). Bonobos and chimpanzees infer the target of an actor's attention. - Anim. Behav. 83: 345-353.

Maclean, E. \& Hare, B. (2013). Spontaneous triadic play in bonobos and chimpanzees. J. Comp. Psychol. 127: 245-255.

Maclean, E. \& Hare, B. (2015). Bonobos and chimpanzees read helpful gestures better than prohibitive gestures. - Behaviour 152: 493-520.

Palagi, E. \& Paoli, T. (2007). Play in adult bonobos (Pan paniscus): modality and potential meaning. - Am. J. Phys. Anthropol. 134: 219-225.

Prufer, K., Munch, K., Hellmann, I., Akagi, K., Miller, J.R., Walenz, B., Koren, S., Sutton, G., Kodira, C., Winer, R., Knight, J.R., Mullikin, J.C., Meader, S.J., Ponting, C.P., Lunter, G., Higashino, S., Hobolth, A., Dutheil, J., Karakoç, E., Alkan, C., Sajjadian, S., Catacchio, C.R., Ventura, M., Marques-Bonet, T., Eichler, E.E., André, C., Atencia, R., Mugisha, L., 
Junhold, J., Patterson, N., Siebauer, M., Good, J.M., Fischer, A., Ptak, S.E., Lachmann, M., Symer, D.E., Mailund, T., Schierup, M.H., Andrés, A.M., Kelso, J. \& Pääbo, S. (2012). The bonobo genome compared to the chimpanzee and human genome. - Nature 486: 527-531.

Rosati, A. (2015). Context influences spatial frames of reference in bonobos (Pan paniscus). - Behaviour 152: 375-406.

Rosati, A.G. \& Hare, B. (2012). Decision making across social contexts: competition increases preferences for risk in chimpanzees and bonobos. — Anim. Behav. 84: 869-879.

Rosati, A. \& Hare, B. (2013). Chimpanzees and bonobos exhibit emotional responses to decision outcomes. - PLoS One 8: e63058.

Ryu, H., Hill, D. \& Furuichi, T. (2015). Prolonged maximal sexual swelling in wild bonobos facilitates affiliative interactions between females. - Behaviour 152: 285-311.

Schroepfer-Walker, K., Wobber, T. \& Hare, B. (2015). Experimental evidence that grooming and play are social currency in bonobos and chimpanzees. - Behaviour 152: 545-562.

Schubert, G., Vigilant, L., Boesch, C., Klenke, R., Langergraber, K., Mundry, R., Surbeck, M. \& Hohmann, G. (2013). Co-residence between males and their mothers and grandmothers is more frequent in bonobos than chimpanzees. — PLoS One 8: e83870.

Stevens, J.M.G., Vervaecke, H., de Vries, H. \& Van Elsacker, L. (2007). Sex differences in the steepness of dominance hierarchies in captive bonobo groups. - Int. J. Primatol. 28: 1417-1430.

Stevens, J., De Groot, E. \& Staes, N. (2015). Relationship quality in captive bonobo groups. — Behaviour 152: 259-283.

Surbeck, M. \& Hohmann, G. (2008). Primate hunting by bonobos at LuiKotale, Salonga National Park. - Curr. Biol. 18: R906-R907.

Surbeck, M., Mundry, R. \& Hohmann, G. (2011). Mothers matter! Maternal support, dominance status and mating success in male bonobos (Pan paniscus). — Proc. Roy. Soc. Lond. B: Biol. Sci. 278: 590-598.

Tan, J. \& Hare, B. (2013). Bonobos share with strangers. — PLoS One 8: e51922.

Tan, J., Kwetuenda, S. \& Hare, B. (2015). Preference or Paradigm? Bonobos do not share in "the" prosocial choice task. - Behaviour 152: 521-544.

Watts, D. \& Mitani, J. (2002). Hunting behaviour of chimpanzees at Ngogo, Kibale National Park, Uganda. - In: Behavioral diversity in chimpanzees and bonobos (Boesch, C., Hohmann, G. \& Marchant, L., eds). Cambridge University Press, Cambridge, p. 244257.

Wilson, M., Boesch, C., Fruth, B., Furuichi, T., Gilby, I.C., Hashimoto, C., Hobaiter, C.L., Hohmann, G., Itoh, N., Koops, K., Lloyd, J.N., Matsuzawa, T., Mitani, J.C., Mjungu, D.C., Morgan, D., Muller, M.N., Mundry, R., Nakamura, M., Pruetz, J., Pusey, A.E., Riedel, J., Sanz, C., Schel, A.M., Simmons, N., Waller, M., Watts, D.P., White, F., Wittig, R.M., Zuberbühler, K. \& Wrangham, R.W. (2014). Lethal aggression better explained by adaptive strategies than by human impact. - Nature 513: 414-417.

Wobber, T. \& Hare, B. (2011). Psychological health of orphan bonobos and chimpanzees in African sanctuaries. - PLoS One 6: e17147. 
Wobber, V. \& Herrmann, E. (2015). The influence of testosterone of cognitive performance in bonobos and chimpanzees. - Behaviour 152: 407-423.

Wobber, V., Wrangham, R. \& Hare, B. (2010a). Evidence for delayed development of social behavior and cognition in bonobos relative to chimpanzees. - Curr. Biol. 20: 226-230.

Wobber, V., Hare, B., Maboto, J., Lipson, S., Wrangham, R. \& Ellison, P. (2010b). Differential reactivity of steroid hormones in chimpanzees and bonobos when anticipating food competition. - Proc. Natl. Acad. Sci. 107: 12457-12462.

Wobber, T., Herrmann, E., Hare, B., Wrangham, R. \& Tomasello, M. (2014). The evolution of cognitive development in Pan and Homo. — Dev. Psychobiol. 5: 547-573.

Wrangham, R. (1999). Evolution of coalitionary killing. - Yb. Phys. Anthropol. 42: 1-30.

Yamamoto, S. (2015). Non-reciprocal but peaceful fruit sharing in the wild bonobos of Wamba. - Behaviour 152: 335-357.

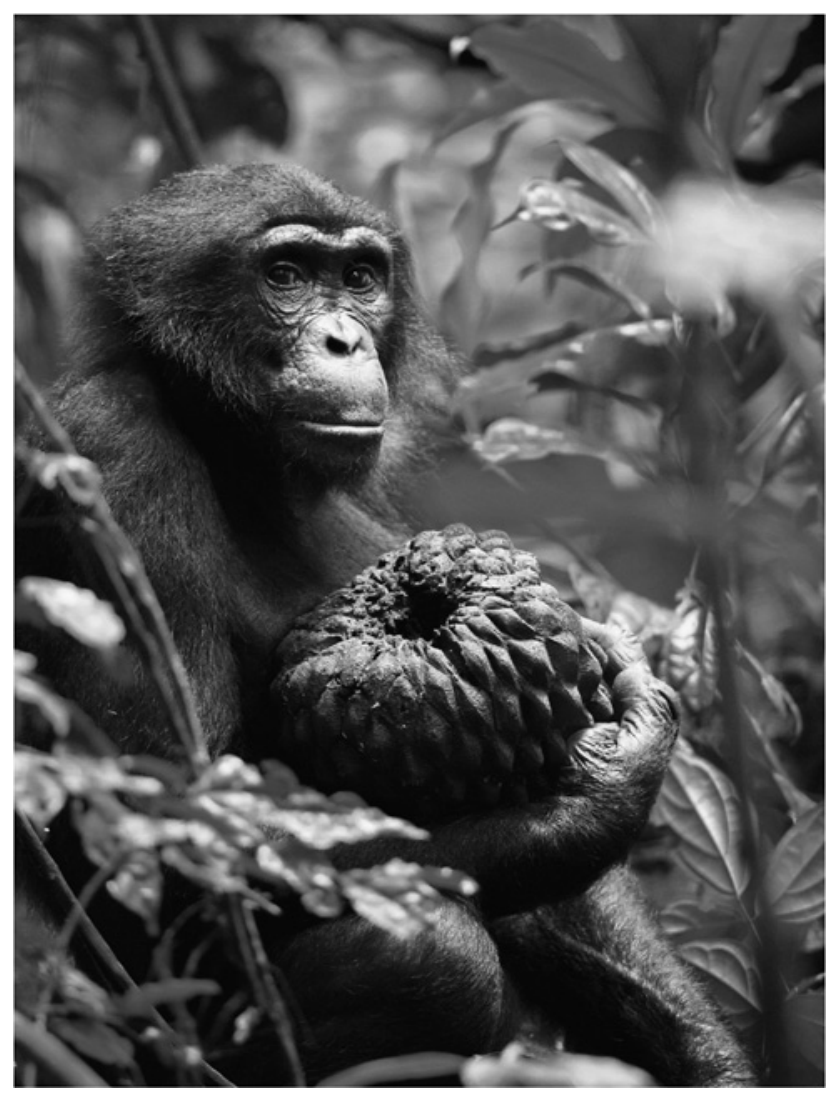

Bonobo (Pan paniscus). Photo taken by Shinya Yamamoto at Wamba, Democratic Republic of the Congo. 